\title{
Thought control strategies predict emotion regulation abilities in patients with frontal lobe epilepsy
}

\author{
Amara Gul* and Hira Ahmad \\ *Correspondence: amara_psychology@hotmail.com

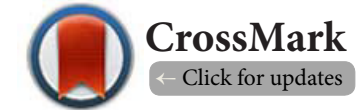

Department of Applied Psychology, The Islamia University of Bahawalpur, Pakistan.

\begin{abstract}
Background: The aim of the present study was to examine whether thought control strategies can determine emotion regulation abilities in patients with frontal lobe epilepsy.

Methods: 35 Patients with frontal lobe epilepsy and 35 healthy individuals completed emotion regulation questionnaire (Gross \& John, 2003) and rated their thoughts on thought control questionnaire (Wells \& Davies, 1994).

Results: Multivariate analysis showed that patients with frontal lobe epilepsy had lower scores on thought control strategies such as distraction, social control, reappraisal and emotion regulation as compared to healthy individuals. In contrast, patients had higher scores on worry and punishment. Pearson correlations revealed that distraction, social control, and reappraisal had significant positive correlation with emotion regulation abilities whereas worry and punishment had inverse correlation with emotion regulation. Linear regression showed that thought control strategies could predict emotion regulation abilities in patients with frontal lobe epilepsy.
\end{abstract}

Conclusions: Results indicate that patients with frontal lobe epilepsy do not benefit from distraction, social control and reappraisal when they regulate emotions. Alongside, worry and punishment interfere with emotion regulation.

Keywords: Emotion, thought, epilepsy, frontal lobe, cognition

\section{Introduction}

\section{Frontal lobe epilepsy}

Frontal lobe epilepsy (FLE) is a neurological condition which involves frequent seizures that arise in frontal lobes [1]. Seizures of the frontal lobe occur in clusters and last for a short duration approximately less than a minute [2]. Patients show repetitive and wild muscular activities, such as bicycling, screaming that is accompanied by tiredness and confusions. Seizures are partial and symptoms depend on the area of the frontal lobe involved. Simple partial seizures do not affect memory and awareness whereas complex partial seizures involve impairment of the memory and awareness [3]. Epilepsy has significant effect on the social well-being and quality of life of the individuals that are distressed with it $[\mathbf{4 , 5}]$. Frontal lobes monitor a wide range of cognitive functions including memory, judgment, problem solving, social behavior and motor activity, therefore people with FLE exhibit education, learning and cognitive function deficits [6]. The effects on cognitive function are enormous in FLE than any other form of epilepsy. On a cognitive level, people with epilepsy have reduced performance on measures of speed, planning, attention span, recall, and concept formation [7]. Patients with epilepsy have deficits in executive planning, working memory, mental flexibility, visuo-spatial organization and anticipatory behavior. Patients show complex motor sequences, hyperactive, addictive and stereotypic bizarre behavior $[8,9]$. Patients with FLE show deficits in social cognition such as to appreciate humor, recognize expressions of emotions, and forecast consequences. Cognitive capacities of people with FLE are limited to response inhibition, selection and initiation, therefore a continuous performance without intrusion and interference errors is hardly seen [10]. FLE is associated with dysfunctions in several regions of the frontal lobe. The following section provides an overview of the critical role of certain regions of the frontal lobe in higher-order cognitive functions. 
Gul et al. Neuroscience Discovery 2015,

\section{Prefrontal cortex and higher-order functions}

Orbital mesiofrontal region of the frontal lobe is connected with structures of the limbic system such as cingulate gyrus, hippocampus and amygdala [11] that regulates emotion, motivation, learning and memory [12], thus complex symptoms arise during epileptic seizures of the focal region [13]. Amygdala is involved in several cognitive processes and impacts episodic-autobiographical memory network monitoring encoding, storage and retrieval. In cognitive terms, amygdala is responsible to activate mnemonics of social and emotional significance in the neural network [14]. It is linked with the ability to modulate attention to the relevant stimuli while ignoring the irrelevant ones [15]. Hippocampus plays influential role in semantic, episodic and spatial memories [16]. Cingulate gyrus links behavioral outcomes to motivation and impacts executive functioning [17].

Frontal lobe plays a role in cognitive development. Ventromedial areas of the prefrontal cortex are involved in the control of emotional expression and higher order executive functions. The key role of the prefrontal cortex is the sequential and time-based organization of goal-directed activities in domains of behavior, emotion, cognition and language. The temporal organization of segregated percepts transforms into coherent structures of actions [18] and working memory acts as driving force for executive functions. The orbital cortex makes up connections and allows attention to be directed to the task relevant stimuli through inhibitory mechanisms and thus reducing interference by the irrelevant stimulus. The anterior cingulate cortex and dorsolateral prefrontal cortexplay significant role in response initiation, intention, selective attention and task management $[19,20]$. The prefrontal cortex manipulates cognitive control such as the ability to synchronize thoughts and actions to achieve goals. Premotor to anterior regions of the prefrontal cortex keep track of the task relevant behavior, perceptual context and the temporal episodes of the stimuli and integrates into a unified modular form of the cognitive control [21]. Prefrontal cortex influences top-down selection in the course of decision-making [22] and integrates information across multiple, specialized and distinct regions [23].

\section{Thought control}

The deliberate attempt to control thoughts most often remains unsuccessful in patients with pathological behaviors [24], for example patients with obsessive-compulsive disorder attempt to neutralize or prevent distressing thoughts that become rather more frequent [25]. Thought control is a common form of mental control that is linked with inhibition. During conditions of high cognitive load, the frequency of unwanted thoughts is increased and such thoughts become rather more accessible to produce intrusion [26,27]. The empirical work on thought control by Wegner and colleagues demonstrated that subjects had frequent occurrence of unwanted thoughts despite the conscious attempt to avoid thinking of the specific thoughts, for example a white bear [28-30]. Thought suppression of emotional content produces neurological symptoms such as depression [31,32]. It has implication in the development, maintenance and treatment of clinical disorders [33]. Individuals who are overwhelmed with unwanted thoughts must concentrate on the attainment of desirable goals, learning effective ways to distract attention, accepting and expressing intrusive thoughts [34]. Cognitive avoidance strategies could also be useful to prevent psychopathological consequences of thought suppression [35]. Wegner and Wenzlaff [36] suggested an interaction between intentional operating process and an ironic monitoring system. The intentional operating process promotes preferred emotional states/unwanted material and directs attention away from the intrusive stimulus whereas the ironic monitoring system traces errors that are responsible for failures to reach the intended state. Once, the operating system gets occupied with preferred emotional states, the monitoring system then takes the charge to fill the consciousness with a changed material. At this stage, mental control is activated to bring mind back to the unwanted material that interrupts the stream of cognitive processes [37].

\section{Emotion regulation}

Emotions are generated when significant things in our life at risk. Emotions have behavioral, physiological and cognitive consequences. Therefore, responses to emotions need to be regulated in order to behave in synchronous manner. Emotion regulation refers to the monitoring of experience and expression of emotions [38]. This involves a change in emotion dynamics for the time, latency, duration and offset of the behavioral, physiological and experiential response [39]. Emotion regulation requires the decrease and maintenance of positive and negative emotions according to the demands of circumstances [40]. This process is executed on the conscious level, for example diverting attention from unwanted thoughts [41]. Emotion regulation is desirable for high level of cognitive performance [42]. Regulation of emotions is associated with increased activation in lateral prefrontal regions and decreased activation of emotion processing regions (i.e., amygdala and medial orbitofrontal cortex) [43].

\section{The present study}

Patients with epileptic and non-epileptic seizures show impaired emotion regulation $[\mathbf{4 4 , 4 5 ]}$. It has also been observed that patients with epileptic seizures with origin in frontal or mesial temporal lobe have deficits in social cognition $[46,47]$. From the above cited literature, researchers got motivation to examine which strategies patients with FLE use to control their cognitions and regulate emotions. There is possibility that patients with FLE use differential strategies for thought control and emotion regulation as compared to healthy individuals. Researchers aimed to compare thought control strategies and emotion regulation in patients with FLE versus healthy individuals. Further, we aimed to examine whether any 
relationship between thought control strategies and emotion regulation exists in patients with FLE and healthy individuals. Few emotion regulation strategies might be associated with thought control strategies that could play a positive role in enhanced cognitive performance such as inhibition and reappraisal $[26,27]$. At the same time, the present study might indicate some strategies that are negatively correlated with cognitive performance such as worry [33].

\section{Hypotheses}

1. Patients with FLE would less frequently use distraction, social control, and reappraisal than healthy subjects.

2. Patients with FLE would more frequently use worry and punishment than healthy subjects.

3. Patients with FLE would have lesser emotion regulation than healthy subjects.

4. Thought control strategies could predict emotion regulation abilities.

\section{Methods \\ Participants}

Thirty-five patients with FLE took part in the study at Jinnah and Services Hospital, Lahore. The inclusion criterion for the study was EEG evidence of the seizure onset in the frontal lobes, MRI evidence of the epileptogenic lesion, average intellectual functioning [48] and no history or current status of psychiatric disorders [49]. Thirty-five healthy subjects were recruited from the university campus. Participants should have no signs or history of neurological and psychiatric disorder, medication use and average intellectual function. Subject groups were matched on gender, age, education and socioeconomic status (for sample characteristics see Table 1).

\section{Instruments}

Emotion regulation questionnaire (ERQ; [50])

$E R Q$ examines the ability of an individual to regulate emotions in daily life. It is a 10 items scale that is scored on a 7-point Likert scale ranging from $1=$ strongly disagree to $7=$ strongly agree. The sale has good psychometric characteristics with test-retest reliability of $a=0.69$.

\section{Thought control questionnaire (TCQ; [51])}

TCQ is a 30-item self-report questionnaire that was developed by Wells and Davies in 1994 to measure several techniques which individuals use to control intrusive and unwanted thoughts. The TCQ provides assessment on five thought control strategies: distraction, social control, worry, punishment, and reappraisal. Distraction reflects thought diversion toward positive aspects of life. Social control examines socially acceptable ways of coping. Worry examines thought residing on other worries. Reappraisal examines thought rationality. Responses are scored on 4-point Likert scale: never $=1$, sometimes $=2$, often $=3$, almost always $=4$. Each subscale has six items: distraction (items 1, 9, 16, 19, 21, 30); social control (items 5, 8, 12, 17, 25, 29); worry (items 4, 7, 18, 22, 24, 26); punishment (items $2,6,11,13,15,28$ ) and reappraisal (items $3,10,14,20,23,27)$. The total score is obtained by cumulative scores on the five subscales. Each subscale has high internal consistency with distraction ( $a=0.72)$; social control $(a=0.79)$; worry ( $\alpha=0.71$ ); punishment ( $a=0.64)$; and reap praisal ( $a=0.67)$ and high test-retest reliability with coefficients ranging from 0.67 to 0.83 across the five subscales [52].

\section{Depression anxiety and stress scale [53]}

The Depression Anxiety and Stress Scale (DASS-42) was designed by Lovibond and Lovibond to score anxiety, depression and stress on a 4-point Likert scale of $0-3$; where $0=$ "not apply to me", and 3="completely apply". The Depression Scale indexes sadness and cognitive problems. Scores are categorized as normal $=0-9$, mild $=10-13$, moderate $=14-20$, and severe $=21-27$. The Anxiety Scale assessesan individual's experience of nervousness. Scores are referred asnormal $=0-7$, mild $=8-9$, moderate $=10-14$, and severe $=15-19$. The Stress Scale examinesanxious arousal as normal $=0-14$, mild $=15-18$, moderate $=19-25$, and severe $=26-33$. DASS is strongly correlated with Beck Anxiety Inventory (0.81) and Beck Depression Inventory (0.74) where as Cronbach's alpha is 0.96 for depression, 0.89 for anxiety, and 0.93 for stress, anxiety.

\section{Mini mental status examination [54]}

The mini mental state examination (MMSE) is a 12 item questionnaire developed by Folstein and colleagues [54]. It is a valid and reliable questionnaire that is widely used in research and clinical settings to measures the cognitive impairment [55]. The administration time is 5 to 10 minutes. MMSE examines several cognitive functions as attention/concentration, calculation, registration, recall and language [56]. MMSE scores of 20 to 24 reflect mild cognitive impairment; MMSE scores of 10-20 are categorized as moderate cognitive impairment; whereas scores below 10 reflect severe cognitive impairment. MMSE scores above 24 reflect normal cognition [57].

\section{Planned statistical analyses}

Statistical analyses will be performed with the SPSS [58].

\section{Group differences}

Group differences will be examined through multivariate analysis of variance on scores of emotion regulation, distraction, social control, worry, punishment and reappraisal as independent factors and group as fixed factor to test between group differences on emotion regulation and subscales of TCQ.

\section{Predictors of emotion regulation}

Predictors of emotion regulation will be examined through regression analyses.

\section{Procedure}

Participants gave informed consent upon arrival at the testing 
Gul et al. Neuroscience Discovery 2015,

http://www.hoajonline.com/journals/pdf/2052-6946-3-1.pdf

Table 1. Characteristics for patients with FLE and healthy control group.

\begin{tabular}{|c|c|c|}
\hline Variables & Patients $(n=35)$ & Control $(n=35)$ \\
\hline Age at the time of testing & $\begin{array}{l}M(\mathrm{SD})(\mathrm{min}-\mathrm{mix}) \\
21.75(1.87)(18.00-25.00)\end{array}$ & $\begin{array}{l}M(\mathrm{SD})(\mathrm{min}-\mathrm{mix}) \\
22.25(1.96)(18.00-25.00)\end{array}$ \\
\hline Age at epilepsy onset & $18.42(1.65)(15.00-22.00)$ & -- \\
\hline \multicolumn{3}{|l|}{ Type of medication } \\
\hline Mono therapy (n) & 17 & -- \\
\hline Poly therapy (n) & 18 & -- \\
\hline \multicolumn{3}{|l|}{ Mental status examination } \\
\hline Orientation & $05(0.02)$ & $07(0.01)$ \\
\hline Registration & $01(0.05)$ & $03(0.01)$ \\
\hline Attention/concentration & $04(0.01)$ & $05(0.02)$ \\
\hline Recall & $01(0.02)$ & $03(0.05)$ \\
\hline Language & $06(0.01)$ & $09(0.02)$ \\
\hline Total & 17 & 27 \\
\hline \multicolumn{3}{|l|}{ Comorbidity } \\
\hline Depression (n) & 03 (mild $M=10.00, \mathrm{SD}=0.5$ ) & None \\
\hline Anxiety (n) & $02($ moderate $M=12.00, \mathrm{SD}=0.2)$ & None \\
\hline Stress (n) & 01 (mild) $M=15.00, \mathrm{SD}=0.3$ ) & None \\
\hline \multicolumn{3}{|l|}{ Gender } \\
\hline Female & 20 & 20 \\
\hline Male & 15 & 15 \\
\hline \multicolumn{3}{|l|}{ Economic status } \\
\hline Lower & -- & -- \\
\hline Middle & 18 & 16 \\
\hline Higher & 12 & 14 \\
\hline \multicolumn{3}{|l|}{ Education } \\
\hline Primary & -- & -- \\
\hline Secondary & 18 & 15 \\
\hline Higher & 17 & 20 \\
\hline \multicolumn{3}{|l|}{ Epilepsy Onset } \\
\hline Right frontal & 16 & -- \\
\hline Left frontal & 19 & -- \\
\hline \multicolumn{3}{|l|}{ Localized abnormality } \\
\hline Prefrontal cortex & 12 & -- \\
\hline Medial & 08 & -- \\
\hline Dorsolateral & 09 & -- \\
\hline Orbitofrontal foci & 06 & -- \\
\hline
\end{tabular}

room. Following their mini mental status examination was conducted. Participants were then instructed to complete ERQ and TCQ. Subjects were thanked for their participation at the end of the testing session.

\section{Results}

Multivariate analysis was performed on scores of distraction, social control, worry, punishment, reappraisal and emotion regulation as independent factors and group as between subject factor. The effect of group was significant on distraction $F(1,68)=75.14, p<0.001, \eta p 2=0.52$, healthy controls $(M=21.14$, $\mathrm{SD}=2.31)$ patients $(M=16.08, \mathrm{SD}=2.55)$; social control $F(1$, $68)=68.96, p<0.001, \mathrm{np} 2=0.50$, healthy controls $(M=21.31$, $\mathrm{SD}=2.09)$ patients $(M=16.48, \mathrm{SD}=2.72)$; worry $F(1,68)=57.48$, 
$p<0.001, \mathrm{np} 2=0.45$, healthy controls $(M=17.02, \mathrm{SD}=2.36)$ patients $(M=21.22, \mathrm{SD}=2.26)$; punishment $F(1,68)=62.48$, $p<0.001, \mathrm{np} 2=0.47$, healthy controls $(M=16.60, \mathrm{SD}=2.73)$ patients $(M=21.40, S D=2.32)$; and reappraisal $F(1,68)=76.61$, $p<0.001, \mathrm{np} 2=0.53$, healthy controls $(M=21.77, \mathrm{SD}=2.27)$ patients $(M=16.68, \mathrm{SD}=2.57)$. Groups also had significant difference on the scores of emotion regulation $F(1,68)=285.52$, $p<0.001, \mathrm{np} 2=0.80$, healthy controls $(M=61.11, \mathrm{SD}=4.78)$ patients $(M=29.40, S D=10.01)$, Figure 1 .

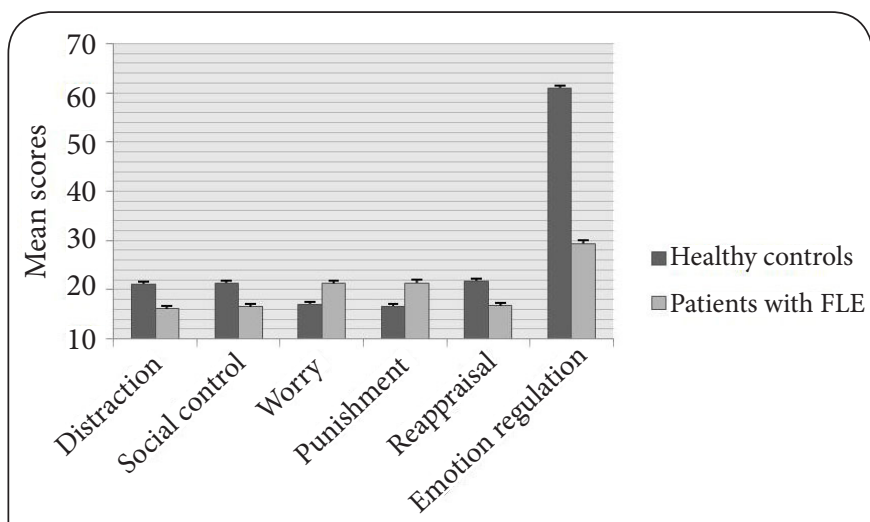

Figure 1. Mean scores on TCQ and ERQ. Error bars represent standard errors.

Pearson correlations were computed to examine the relationship between emotion regulation and thought control strategies. Emotion regulation had significant positive correlation with distraction $(r=0.90, p<0.001)$, social control $(r=0.89$, $p<0.001)$, and reappraisal $(r=0.89, p<0.001)$. In contrast, emotion regulation had an inverse correlation with worry $(r=-0.53$, $p<0.001)$ and punishment $(r=-0.55, p<0.001)$, Table 2. Linear regression analysis with emotion regulation as dependent while age, gender, group, age at epilepsy onset, seizure frequency, type of medication, and TCQ scores as independent variables showed significant result $F(7,69)=101.79, p<0.001$, $\mathrm{R}^{2}=0.92$. $\mathrm{TCQ}$ scores were significant predictor of emotion regulation in patients with FLE $\beta=0.35, t=9.04, p<0.001$. In contrast, none of the sample characteristics could successfully predict emotion regulation scores:age $\beta=-0.01, t=-0.43$, $p=0.66$, gender $\beta=-0.01, t=-0.31, p=0.75$, group $\beta=-0.18, t=-$ $0.35, p=0.72$, age at epilepsy $\beta=0.46, t=1.40, p=0.16$, seizure frequency $\beta=0.12, t=0.26, p=0.79$, and type of medication $\beta=0.01, t=0.28, p=0.77$.

\section{Discussion and conclusions}

The present study was designed to compare thought control strategies employed by patients with FLE versus healthy individuals. Second, we were interested to compare whether emotion regulation abilities differ in patients with FLE than healthy individuals. Further, we examined the relationship between thought control strategies and emotion regulation. Our results showed that patients with FLE has lesser scores on thought control strategies such as distraction, social control, and reappraisal than healthy subjects. In contrast, patients with FLE exhibited higher scores on worry and punishment as compared to healthy subjects. This finding can be interpreted in the context that patients with FLE show deficits in broad domains of education, learning, and cognitive functions [6]. Therefore, they experience poor quality of life $[59,60]$. Patients have impaired performance during recall, planning, and concept formation [7]. Their attention span is short and speed to perform cognitive functions is also slow. Patients with epilepsy show reduced efficiency on executive functions, working memory, mental flexibility, and spatial organization. On behavioral level, patients show complex motor sequences, hyperactive, addictive and stereotypic bizarre behavior $[\mathbf{8}, \mathbf{9}]$. Patients with FLE have deficits in social cognition, for instance the capability to appreciate humor, recognize expressions, and forecast consequences is constrained. At this point, we summarize that FLE is associated with cognitive function deficiencies, and performance on cognitive, social, and learning tasks remains error prone [10]. Our finding illustrates that patients with FLE have weaker thought control than healthy individuals, thus they have limited cognitive resources to concentrate on any task. The efficiency on cognitive tasks remains vulnerable to intrusive and unwanted thoughts that may hinder normal flow of the cognitive, social and emotional functioning. On physiological level, FLE is connected with dysfunctions of the frontal lobe. Frontal lobe contain important structures that monitor emotion, memory, learning, and cognition [11-13]. It is involved in encoding, storage,

Table 2. Pearson correlations between scores on ER and subscales of TCQ.

\begin{tabular}{|c|c|c|c|c|c|c|c|}
\hline & ER & Distraction & SC & Worry & Punishment & Reappraisal & Total TCQ \\
\hline ER & -- & $0.90^{* *}$ & $0.89^{\star \star}$ & $-0.53^{\star *}$ & $-0.55^{\star *}$ & $0.89^{* *}$ & $0.58^{\star *}$ \\
\hline Distraction & $0.90^{* *}$ & -- & $0.97^{\star \star}$ & $-0.36^{\star *}$ & $-0.36^{\star *}$ & $0.97^{\star *}$ & $0.79^{\star *}$ \\
\hline SC & $0.89^{\star *}$ & $0.97^{\star *}$ & -- & $-0.34^{\star *}$ & $-0.36^{\star *}$ & $0.96^{\star *}$ & $0.79^{* *}$ \\
\hline Worry & $-0.53^{\star *}$ & $-0.36^{\star *}$ & $-0.34^{\star *}$ & -- & $0.95^{\star *}$ & $-0.39^{* *}$ & $0.26^{\star}$ \\
\hline Punishment & $-0.55^{\star \star}$ & $-0.36^{\star *}$ & $-0.36^{\star *}$ & $0.95^{\star \star}$ & -- & $-0.40^{* *}$ & $0.25^{\star}$ \\
\hline Reappraisal & $0.89^{* *}$ & $0.97^{\star \star}$ & $0.96^{\star *}$ & $-0.39^{* *}$ & $-0.40^{* *}$ & -- & $0.76^{\star *}$ \\
\hline Total TCQ & $0.58^{\star \star}$ & $0.79^{* *}$ & $0.79^{\star \star}$ & $0.26^{*}$ & $0.26^{*}$ & $0.76^{* *}$ & -- \\
\hline
\end{tabular}

Note: ER=Emotion regulation; $\mathrm{SC}=$ Social control; ${ }^{\star *} \mathrm{p}<0.001 .{ }^{\star} \mathrm{p}<0.05$. 
Gul et al. Neuroscience Discovery 2015,

retrieval and activation of mnemonics that have social and emotional significance $[14,16,17]$. Amygdala is involved in the ability to modulate attention towards relevant stimuli while ignoring the irrelevant ones [15]. Frontal lobe is involved in cognitive development. Ventromedial areas of the prefrontal cortex controls emotion expressions, goal-directed activities, higher order executive functions and temporal organization of segregated percepts to transforms into coherent structures of actions [18]. The orbital cortex sets up neural connections to be direct attention towards task relevant stimuli through inhibitory mechanisms. The anterior cingulate cortex and dorsolateral prefrontal cortex are responsible for response initiation, intention, selective attention and task management $[19,20]$. Most important, prefrontal cortex exerts cognitive control to synchronize thoughts and actions for goal achievement [21]. Prefrontal cortex influences top-down selection to make decisions and compiles information across multiple, specialized and distinct regions $[22,23]$.

Thought control is associated with well-being and health [33]. Failure to control thoughts is associated with pathological behaviors, for example people with anxiety disorders do not have control on anxiety-related thoughts $[24,25,31,32]$. Control on thoughts is a form of mental exercise that is linked with inhibition. Unwanted thoughts have the potential to become highly accessible to produce intrusion $[\mathbf{2 6 , 2 7 ]}$ specifically when an individual attempts to avoid such thoughts [28-30]. Our results demonstrated that patients with FLE have abnormal cognitive functioning in the domains of concentration, attention and memory. Patients with FLE showed weaker cognitive control on thoughts and emotion regulation as compared with healthy controls. Patients remain unable to divert their thinking mode, adopt healthy coping styles and rationality as illustrated by higher scores on worry and punishment than healthy controls. In contrast, these strategies of thinking and emotion regulation did not appear in healthy individuals. The process of emotion regulation requires diversion of attention from unwanted thoughts [41], a form of control which is deficient in patients with FLE. Emotion regulation again involves lateral prefrontal regions, amygdala and medial orbitofrontal cortex [43].

The hypothesis of current study that thought control strategies could predict emotion regulation was found significant. We included characteristics of the sample to separate out the effects of clinical and demographic variables but we found none of the variables as significant predictor of the emotion regulation. This result depicts that people with deficient thought control have weaker emotion regulation abilities. These results have implications for psychiatrists, the rapists and health care professionals to deal with epileptic patients. The study suggests that emotion regulation and thought control mechanisms must be considered as an important element of the psychosocial assessment of epileptic patients. Thought control exercises must be designed for patients with FLE that may improve deficient cognitive functioning as well as emotion regulation abilities. Training in thought control may enhance attentional diversion from the intrusive material that persists in memory. This practice may improve efficiency of the cognitive system and speeds up rehabilitation process.

\section{Competing interests}

The authors declare that they have no competing interests.

Authors' contributions

\begin{tabular}{|l|c|c|}
\hline Authors' contributions & AG & HA \\
\hline Research concept and design & $\checkmark$ & -- \\
\hline Collection and/or assembly of data & $\checkmark$ & $\checkmark$ \\
\hline Data analysis and interpretation & $\checkmark$ & -- \\
\hline Writing the article & $\checkmark$ & -- \\
\hline Design of figures & $\checkmark$ & -- \\
\hline Critical revision of the article & $\checkmark$ & -- \\
\hline Final approval of article & $\checkmark$ & $\checkmark$ \\
\hline Statistical analysis & $\checkmark$ & $\checkmark$ \\
\hline
\end{tabular}

Acknowledgement

Authors are thankful to all subjects who took part in the study.

Publication history

EIC: Tadanori Tomita, Northwestern University Feinberg School of Medicine, USA.

Received: 16-Aug-2014 Final Revised: 09-Jan-2015

Accepted: 23-Jan-2015 Published: 02-Feb-2015

\section{References}

1. Frontal lobe seizures: Symptoms. Diseases and Conditions. Mayoclinic. com. 2008-10-11. | Website

2. Panayiotopoulos C. Symptomatic and Probably Symptomatic Focal Epilepsies: Topographical Symptomatology and Classification. "The Epilepsies". Blandon Medical Publishing. 2005. I PubMed

3. Kramer U, Riviello JJ, Jr., Carmant L, Black PM, Madsen J and Holmes GL. Clinical characteristics of complex partial seizures: a temporal versus a frontal lobe onset. Seizure. 1997; 6:57-61. | Article | PubMed

4. Living With Epilepsy. 2009. | Website

5. Wellness and Quality of Life Kit. 2009. | Website

6. Helmstaedter C. Behavioral Aspects of Frontal Lobe Epilepsy. Epilepsy Behav. 2001; 2:384-395. | Article | PubMed

7. Patrikelis $P$, Angelakis $E$ and Gatzonis $S$. Neurocognitive and behavioral functioning in frontal lobe epilepsy: a review. Epilepsy Behav. 2009; 14:19-26. | Article | PubMed

8. Helmstaedter C, Kemper B and Elger CE. Neuropsychological aspects of frontal lobe epilepsy. Neuropsychologia. 1996; 34:399-406. | Article | PubMed

9. Riggio S. Behavioral manifestations of frontal lobe seizures. CNS Spectr. 2009; 14:66-70. I PubMed

10. Farrant A, Morris RG, Russell T, Elwes R, Akanuma N, Alarcon G and Koutroumanidis $M$. Social cognition in frontal lobe epilepsy. Epilepsy Behav. 2005; 7:506-16. | Article | PubMed

11. Eichenbaum $\mathrm{H}$. Comparative cognition, hippocampal function, and recollection. Comparative Cognition \& Behavior Reviews. 2007; 2:47-66. I Pdf

12. Kandel ER, Schwartz JH and Jessel TM. Principles of Neural Science, Elsevier, New York, 1991.

13. Iversen SD. Recent advances in the anatomy and chemistry of the limbic system. In M.R. Trimble and E. Zarifian (Eds.), Psychopharmacology of the Limbic System, Oxford University Press, Oxford, 1984; 1-16.

14. Markowitsch $\mathrm{HJ}$ and Staniloiu A. Amygdala in action: relaying biological and social significance to autobiographical memory. Neuropsychologia. 2011; 49:718-33. | Article | PubMed 
15. Pessoa L. Emotion and cognition and the amygdala: from "what is it?" to "what's to be done?". Neuropsychologia. 2010; 48:3416-29. | Article | PubMed Abstract | PubMed Full Text

16. Chung CP, Hsu HY, Chao AC, Chang FC, Sheng WY and Hu HH. Detection of intracranial venous reflux in patients of transient global amnesia. Neurology. 2006; 66:1873-7. | PubMed

17. Hayden BY and Platt ML. Neurons in anterior cingulate cortex multiplex information about reward and action. J Neurosci. 2010; 30:3339-46. I Article | PubMed Abstract | PubMed Full Text

18. Fuster JM. Frontal lobe and cognitive development. J Neurocytol. 2002; 31:373-85. | Article | PubMed

19. Jodar-Vicente M. [Cognitive functions of the frontal lobe]. Rev Neurol. 2004; 39:178-82. | Article | PubMed

20. Smith EE and Jonides J. Storage and executive processes in the frontal lobes. Science. 1999; 283:1657-61. | Article | PubMed

21. Koechlin $E$, Ody $C$ and Kouneiher F. The architecture of cognitive control in the human prefrontal cortex. Science. 2003; 302:1181-5. | Article | PubMed

22. Kouneiher F, Charron S and Koechlin E. Motivation and cognitive control in the human prefrontal cortex. Nat Neurosci. 2009; 12:939-45. | Article I PubMed

23. Koechlin E and Summerfield C. An information theoretical approach to prefrontal executive function. Trends Cogn Sci. 2007; 11:229-35. | Article I PubMed

24. Wegner DM. White bears and other unwanted thoughts: Suppression, obsession, and the psychology of mental control. London: The Guilford Press. 1989.

25. Purdon C. Empirical investigations of thought suppression in OCD. J Behav Ther Exp Psychiatry. 2004; 35:121-36. | Article | PubMed

26. Wegner DM, Erber R and Zanakos S. Ironic processes in the mental control of mood and mood-related thought. J Pers Soc Psychol. 1993; 65:1093-104. | Article | PubMed

27. Wenzlaff RM and Bates DE. The Relative Efficacy of Concentration and Suppression Strategies of Mental Control. Personality and Social Psychology Bulletin. 2000; 26:1200-121. | Article

28. Wegner DM. Ironic processes of mental control. Psychol Rev. 1994; 101:34-52. | Article | PubMed

29. Wegner DM, Schneider DJ, Carter SR and White TL. Paradoxical effects of thoughts suppression. Journal of Personality and Social Psychology. 1987; 53:5-13. I Pdf

30. Clark DM, Ball S and Pape D. An experimental investigation of thought suppression. Behav Res Ther. 1991; 29:253-7. | Article | PubMed

31. Roemer $L$ and Borkovec TD. Effects of suppressing thoughts about emotional material. J Abnorm Psychol. 1994; 103:467-74. | Article PubMed

32. Wenzlaff RM, Wegner DM and Roper DW. Depression and mental control: the resurgence of unwanted negative thoughts. J Pers Soc Psychol. 1988; 55:882-92. | Article | PubMed

33. Purdon C. Thought suppression and psychopathology. Behav Res Ther. 1999; 37:1029-54. | Article | PubMed

34. Wenzlaff RM and Wegner DM. Thought suppression. Annu Rev Psychol. 2000; 51:59-91. | Article | PubMed

35. Rassin E, Merckelbach $\mathrm{H}$ and Muris P. Paradoxical and less paradoxical effects of thought suppression: a critical review. Clin Psychol Rev. 2000 20:973-95. | Article | PubMed

36. Wegner DM and Wenzlaff RM. Mental control. In Higgins E. T. Kruglanski A. W. (Eds.), Social psychology: Handbook of basic principles. New York, NY: Guilford Press. 1996; 466-492.

37. Wenzlaff RM and Bates DE. Unmasking a cognitive vulnerability to depression: how lapses in mental control reveal depressive thinking. $J$ Pers Soc Psychol. 1998; 75:1559-71. | Article | PubMed

38. Gross JJ. The emerging field of emotion regulation: An integrative review. Review of General Psychology. 1998; 2:271-299.

39. Thompson RA. Emotion and self-regulation. In R. A. Thompson Ed., Socioemotional development. Nebraska Symposium on Motivation. Lincoln: University of Nebraska Press. 1990; 36:367-467.

40. Parrott WG. Beyond hedonism: Motives for inhibiting good moods and for maintaining bad moods. In D. M. Wegner \& J. W. Pennebaker. Eds. Handbook of mental control. Englewood Cliffs, NJ: Prentice Hall. 1993; 278-308.
41. Cole PM. Children's spontaneous control of facial expression. Child Development. 1986; 57:1309-1321. | Article

42. Richards JM and Gross JJ. Emotion regulation and memory: the cognitive costs of keeping one's cool. J Pers Soc Psychol. 2000; 79:41024. | Article | PubMed

43. Ochsner KN, Bunge SA, Gross JJ and Gabrieli JD. Rethinking feelings: an FMRI study of the cognitive regulation of emotion. J Cogn Neurosci. 2002; 14:1215-29. | Article | PubMed

44. Gul A and Ahmad H. Cognitive deficits and emotion regulation strategies in patients with psychogenic nonepileptic seizures: a task-switching study. Epilepsy Behav. 2014; 32:108-13. | Article | PubMed

45. De Taeye L, Pourtois G, Meurs A, Boon P, Vonck K, Carrette E and Raedt R. Preserved attention allocation but impaired emotion regulation in epilepsy with comorbid negative affect: electrophysiological time course. Front. Hum. Neurosci. Conference Abstract: Belgian Brain Council 2014 MODULATING THE BRAIN: FACTS, FICTION, FUTURE. 2014. I Article

46. Schacher M, Winkler R, Grunwald T, Kraemer G, Kurthen M, Reed V and Jokeit $\mathrm{H}$. Mesial temporal lobe epilepsy impairs advanced social cognition. Epilepsia. 2006; 47:2141-6. | Article | PubMed

47. Farrant A, Morris RG, Russell T, Elwes R, Akanuma N, Alarcon G and Koutroumanidis M. Social cognition in frontal lobe epilepsy. Epilepsy Behav. 2005; 7:506-16. I Article | PubMed

48. Ravens JC. Guide to using Progressive Matrices. London: The Director of Psychological Research. 1938.

49. American Psychiatric Association. Diagnostic and Statistical Manual of Mental Disorders (4th ed.). American Psychiatric Association, Washington, DC. 1994.

50. Gross JJ and John OP. Individual differences in two emotion regulation processes: implications for affect, relationships, and well-being. J Pers Soc Psychol. 2003; 85:348-62. | Article I PubMed

51. Wells A and Davies MI. The Thought Control Questionnaire: a measure of individual differences in the control of unwanted thoughts. Behav Res Ther. 1994; 32:871-8. | Article | PubMed

52. Reynolds $M$ and Wells $A$. The Thought Control Questionnaire-psychometric properties in a clinical sample, and relationships with PTSD and depression. Psychol Med. 1999; 29:1089-99. | Article | PubMed

53. Lovibond SH and Lovibond PF. Manual for the Depression Anxiety Stress Scale. Psychology Foundation, Sydney. 1995.

54. Folstein MF, Folstein SE and McHugh PR. "Mini-mental state". A practical method for grading the cognitive state of patients for the clinician. $J$ Psychiatr Res. 1975; 12:189-98. I Article I PubMed

55. Pangman VC, Sloan J and Guse L. An examination of psychometric properties of the mini-mental state examination and the standardized mini-mental state examination: implications for clinical practice. Appl Nurs Res. 2000; 13:209-13. I Article I PubMed

56. Tuijl JP, Scholte EM, de Craen AJ and van der Mast RC. Screening for cognitive impairment in older general hospital patients: comparison of the Six-Item Cognitive Impairment Test with the Mini-Mental State Examination. Int J Geriatr Psychiatry. 2012; 27:755-62. | Article | PubMed

57. Mungas D. In-office mental status testing: a practical guide. Geriatrics. 1991; 46:54-8. I PubMed

58. IBM Corp. IBM SPSS Statistics for Windows, Version 20.0. Armonk, NY: IBM Corp. 2011.

59. Helmstaedter C. Behavioral Aspects of Frontal Lobe Epilepsy. Epilepsy Behav. 2001; 2:384-395. | Article | PubMed

60. Shulman MB. The Frontal Lobes, Epilepsy, and Behavior. Epilepsy Behav. 2000; 1:384-395. | Article | PubMed

\section{Citation}

Gul A and Ahmad H. Thought control strategies predict emotion regulation abilities in patients with frontal lobe epilepsy. Neurosci Discov. 2015; 3:1. http://dx.doi.org/10.7243/2052-6946-3-1 